\title{
INCORPORATING BICYCLES INTO URBAN MOBILITY: AN OPPORTUNITY FOR SUSTAINABLE DEVELOPMENT
}

\begin{abstract}
This paper addresses the new role of bicycles as a mode of sustainable urban transport in several cities, after decades of being seen as a minor means of transport. Socio-economic changes over the last few decades and demands from a much more aware public are facilitating the re-incorporation of bicycles into areas not only where they are normally found, such as northern European countries, but also into less usual places, like Spain. In this context, this research aims to assess how much access the public has to various cycling infrastructures, such as bicycle lanes or bike-sharing stations. It also delves into how urban planning and management have made it possible to bicycles in the urban scene, also the main challenges and difficulties to be overcome to make full integration. The analysis includes drawing up themed maps to assess accessibility in the city of Zaragoza in Spain, one of the examples of a change in urban mobility towards a more sustainable system.
\end{abstract}

Keywords: Sustainable transport, bicycle, cycling infrastructures, accessibility.

\section{Introduction}

In Europe, bicycles used to be the usual form of transport in several cities in countries such as Holland, Belgium, Denmark, Germany, France and northern Italy; however, after the Second World War, there was a major shift in urban and metropolitan mobility towards motor vehicles [1], which became the norm for urban transport in western cities and countries [2]. The rise in the price of fuel caused by the oil crisis in the 1970s, together with a period of response and social change, made bicycles resurface as a real alternative transport in certain situations [3]. Thus, after several years in decline [4], cycling went from being a leisure activity or minor form of transport to an element of growing importance in urban journeys [1].

This socio-cultural transformation, focused on a demand for healthier, more environmentally sustainable lifestyles, started in northern European countries, especially the cities that are now a benchmark worldwide for sustainable urban mobility, such as Copenhagen [5 and 6], Amsterdam and Utrecht [7 and 8]. This trend shift, which was put forward as part of the solution to increasing urban and environmental problems (traffic jams, air and noise pollution, loss of quality of life, etc.), could also be found elsewhere in Europe and North America [9]. Deserving mention is the radical MAB
-Le Monde a Bicyclette- movement in Montreal in 1975, and in medium-sized cities in Europe, such as Geneva and Toulouse, which in the 1980s made managing the use of bicycles into a policy objective [1].

More recently, European organizations have encouraged a new urban, environmentally sustainable mobility model [10] which is forcing public administrations to support initiatives catering for the latest provisions and policies on transport [5 and 11]. This has led cities in Europe to institute measures to adopt sustainable urban mobility models like the bicycle, coming late to countries, such as those of the Mediterranean, little used to cycling as a normal form of transport [12]. Nevertheless, from the beginning of the 21 st century, bicycles have been very actively included into the urban mobility of several cities in southern Europe [13].

Most research on the subject has centred on planning sustainable mobility and its urban infrastructure [13 - 16 and 17], on its effect on urban areas and mobility [18 - 20], and on identifying attitudes and conflicts brought about by incorporating bicycles into cities [12, 21, 22 and 23].

Therefore, this paper aims to focus on less researched aspects, such as assessing the bicycle as a means of transport to promote sustainable urban development and allow more balanced access to facilities and services [9]. The city of Zaragoza in Spain was chosen to carry out the case study as

\footnotetext{
* ${ }^{1}$ Carlos Lopez-Escolano, ${ }^{1}$ Angel Pueyo Campos, ${ }^{1}$ Sergio Valdivielso Pardos, ${ }^{2}$ Eva Nedeliakova, ${ }^{2}$ Vladimira Stefancova

${ }^{1}$ University of Zaragoza, The Environmental Sciences Institute of Aragon, Department of Geography and Territorial Planning, Spain

${ }^{2}$ University of Zilina, Faculty of Operation and Economics of Transport and Communications, Department of Railway Transport, Slovakia

E-mail: cle@unizar.es
} 
it has recently implemented a number of policies and actions to promote use of the bicycle as a normal mode of transport.

\section{Incorporating bicycle transport into cities in Spain}

Unlike other countries in this context, support from institutions and businesses for implementing bicycles as a means of transport in Spanish cities has come about only recently [12]. Special attention has been paid to building specific infrastructures, such as cycle lanes and bike-sharing schemes [13]. Consequently, bicycles still do not represent a significant percentage of transport modes in Spanish cities, although their importance has been growing lately. Thus, in 2011, 7.4\% of the population said that they cycled to their destinations daily or almost daily, and $40.3 \%$ did so frequently. These values rose in 2015 to $10 \%$ and $49.6 \%$ respectively [24]. Besides investment in infrastructure and encouraging this mobility mode, other factors have influenced this increase, such as the public deeming the bicycle to be a normal mode of transport, whereas this was not the case before [12], further strengthened by falling living standards due to the effects of the economic crisis [25].

In this context, there have been several successes in integrating bicycles as another means of transport within mobility plans in cities in Spain. Among these are Barcelona, Valencia, Seville, Victoria-Gasteiz and Zaragoza [13 and 24].

A profile of bicycle use in Spanish cities (Table 1) shows that, by 2014, it was a normal means for the public to move around cities like Valencia, Vitoria-Gasteiz, Zaragoza and Seville, where over $35 \%$ of the people used it at least once a week, while Madrid and Bilbao still did not reach more than $20 \%$. This situation can be associated with the degree of users' satisfaction with infrastructure, traffic conditions, distance, terrain, climate, the chance to interchange with another mode of transport, and the availability of cycle parking.

In this respect, planning and implementing cycling infrastructure has been one of the actions with greatest impact in achieving some success in incorporating bicycles into sustainable urban mobility. Over the last few years in Spain, there have been two main developments towards this - building cycle lanes and starting up bike-sharing schemes. The new cycle lanes have provided cycle journeys with quality, speed and safety, while also avoiding disputes with other road users. As for bike-sharing schemes, according to Fishman's paper [26], these have become fairly important in Spain, since it has been widely implemented in several cities (Fig. 1). Thus, Barcelona stands out as the pioneer of incorporating this scheme in Spain in 2012 [27], and is placed among the top positions worldwide, as there are 3.7 public bicycles available for each 1,000 inhabitants. The most successful example of integrating cycling into urban mobility in Spain is Seville,

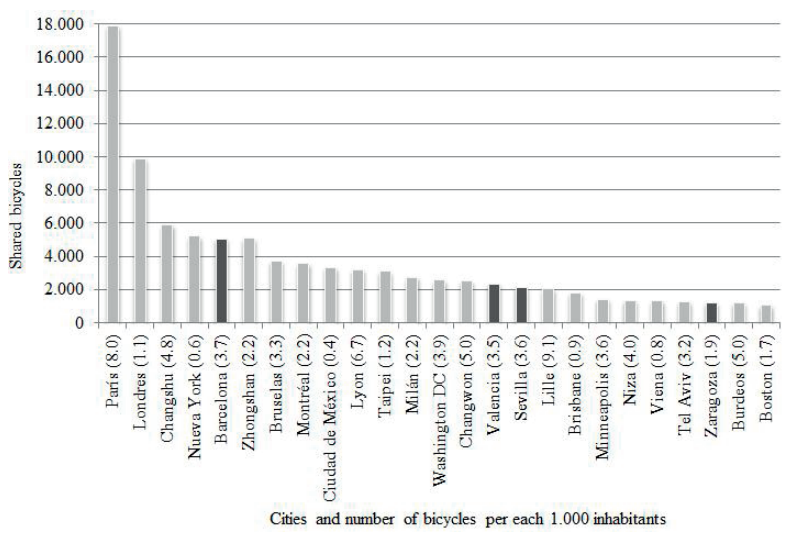

Fig. 1 Number of total shared bicycles available and number of bicycles per inhabitant in 2014 [26 - 27 and 28]

Use of bicycle and degree of satisfaction by city in 2014

Table 1

\begin{tabular}{|l|c|c|}
\hline \multicolumn{1}{|c|}{ City } & $\begin{array}{c}\text { Use once a week or more } \\
\text { (\% of population) }\end{array}$ & $\begin{array}{c}\text { Global satisfaction degree } \\
(0-100)\end{array}$ \\
\hline Valencia & 47 & 65 \\
\hline Vitoria-Gasteiz & 46 & 71 \\
\hline Zaragoza & 45 & 64 \\
\hline Palma de Mallorca & 37 & 78 \\
\hline Sevilla & 35 & 56 \\
\hline Málaga & 28 & 72 \\
\hline Donostia-San Sebastián & 25 & 59 \\
\hline Barcelona & 24 & 36 \\
\hline Madrid & 19 & 50 \\
\hline Bilbao & 17 & \\
\hline
\end{tabular}

Source: [24] 
where 5\% of all urban journeys between 2006 and 2011 were made by bicycle [13]. Seville's scheme was carried out with a relatively small investment in infrastructure, thanks to proper design and management of a cycle lane network that has facilitated the use of bicycles [13]. Identifying features in the cycling mobility model in Seville are continuity, connectivity, homogeneity, visibility, comfort and speedy implementation of the project [13].

\section{The case of Zaragoza}

As with other Spanish cities, Zaragoza, with a population of 665,000 has experienced the introduction and growth of cycle journeys over the last few years. The interest of municipal officials in promoting a more sustainable mobility without the combustion engine led to drafting the Sustainable Mobility Plan in 2006 [29], including sustainable modes of transport like trams and bicycles. In 2008, to coincide with the city holding the International Exhibition, a number of actions were started on urban infrastructures through an investment plan which included designing a road network giving pedestrian and cycling access to the exhibition ground [12 and 19].

At the same time, an increase in the use of bicycles was quickly seen on the city's streets. In 2013, 7.4\% of the population used bicycles as a normal way of getting to work, double the number recorded in 2007 [30]. In this respect, the main reasons for the model's success were: extending the cycle lane network, starting up the Bizi bike-sharing scheme consisting of 130 stations and 1,300 bikes, and municipal regulations allowing bicycles to travel on a good many streets and pavements [12].

\section{Analysis to assess accessibility by bicycle}

One of the main objectives of the Intermodal Transport Plan of 2006 [29] was to make this scheme work by improving the share of pedestrian and cycling modes and obtaining appropriate access to urban facilities and services. In order to be able to assess the effects of bicycles on public access and urban facilities, the cycle lanes, Bizi stations, the city's main structural facilities (administrative, health, university, sports, shopping centres, and tourism and culture), public transport stops (tram and local trains), and the population for each block with information updated to 2015, were added to a Geographical Information System.

Later, a spatial analysis method calculated the public's access from the centroid of each block of buildings and Bizi stations to the cycle lane network, in distances of 150, 300 and 500 metres. The distances were also used to measure access to Bizi stations for the public structural facilities. Shorter distances were used for access to Bizi stations from trams and local trains: 50, 100 and 150 metres -which are thought to generate new routes and increase potential distances of transport in the city using a combined model that includes bicycles-. However, this method of analysis does not include privately owned bicycles, so the opportunities for using intermodal options of travel that include cycling are much higher.

First, cycle lanes were analysed for accessibility for the public and from Bizi stations (Fig. 2). The results show that the public has very high access: $59.91 \%$ of the population is less than $150 \mathrm{~m}$. away from a cycle lane, $84.26 \%$ at less than $300 \mathrm{~m}$., and $93.89 \%$ at less than $500 \mathrm{~m}$. The number of Bizi stations near the cycle lane network is equally high: $57.69 \%$ are

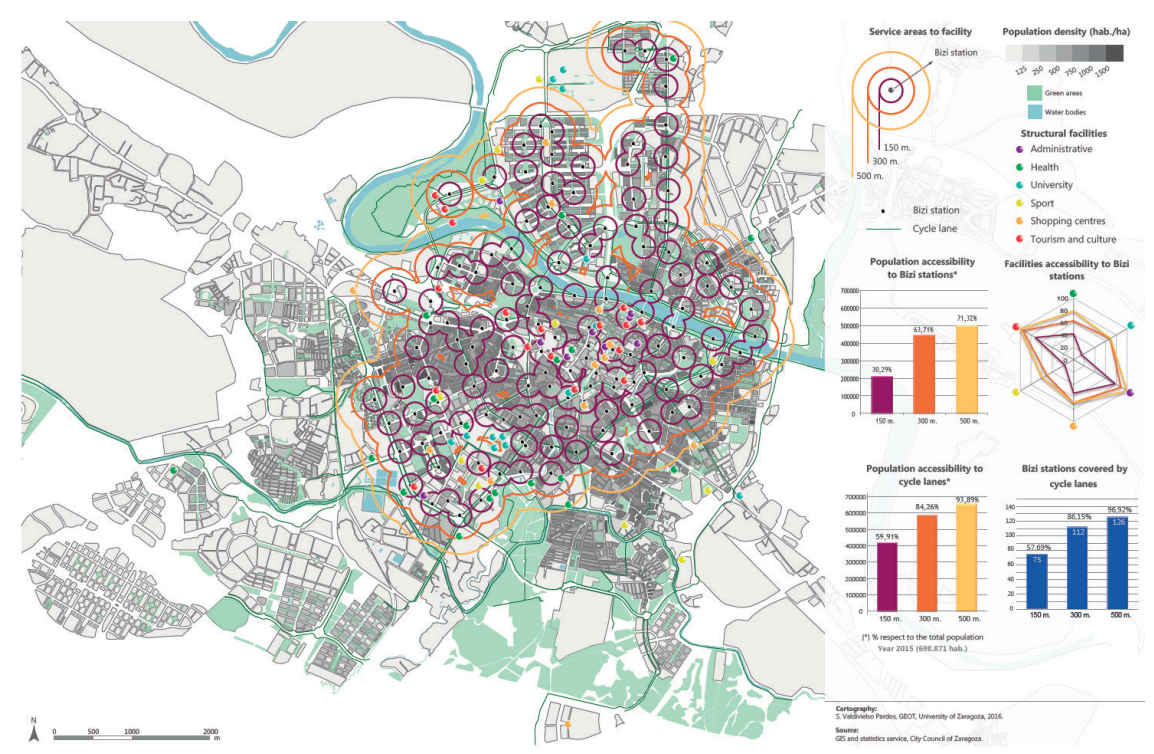

Fig. 2 Accessibility from structural facilities [12] 


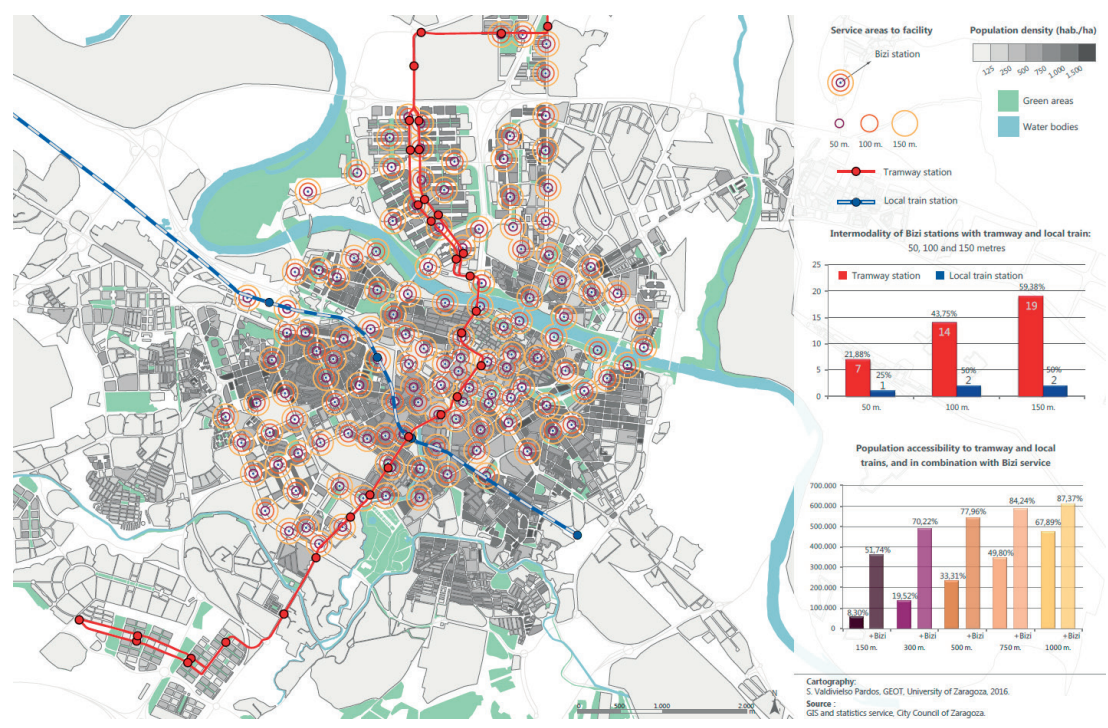

Fig. 3 Potential intermodality of the Bizi schme with trams and local trains [12]

less than $150 \mathrm{~m}$. away, $86.15 \%$ at less than $300 \mathrm{~m}$. and $96.92 \%$ at less than $500 \mathrm{~m}$.

Second, the proximity of Bizi bike-share stations to the public and urban facilities was analysed (Fig. 2). 50.25\% of the population was less than $150 \mathrm{~m}$. away from a Bizi station, rising to $68.33 \%$ at less than $300 \mathrm{~m}$. and $74.79 \%$ at less than $500 \mathrm{~m}$. Accessibility from the main urban facilities to Bizi stations showed that most of the stations in the scheme were adequately located. The best results were obtained for stations at tourism and cultural sites and at facilities, with almost $100 \%$ of these located at less than 300 metres from a Bizi station. There was worse access from shopping centres, health facilities and university sites, with only $60 \%$ to $70 \%$ of stations found at less than $300 \mathrm{~m}$. away. On the other hand, sports centres were the least accessible, with just over $50 \%$ standing at less than $300 \mathrm{~m}$. away.

Lastly, the potential intermodality was analysed for bicycles with other means of transport where bicycle access is possible (Fig. 3), such as trams and local trains.

These results show that most of the public and the structural facilities have good access to cycling infrastructure [31].

\section{Conclusions}

In a "post-carbon" society" [32] that is increasingly demanding new choices and profound change in transport models, bicycles have proved to be an effective alternative for urban mobility in several contexts. Moreover, it is an option that generates numerous benefits for society, the economy, the environment and human health [33]. In practice, such a social change would lead to a different urban scene and behaviour after decades of dominance by private vehicles taking priority [12], since the incorporation of bicycles substantially alters the distribution of transport modes, and encourages a transformation of public spaces to promote compatibility with private vehicles, taxis, buses, trams bicycles and pedestrians [18].

Spain still has to learn from the policies carried out in other European countries - Holland, Denmark and Germany [34] - and copy their measures to encourage a more sustainable urban mobility. To this end, it is essential for cycling to spread and become completely normal as a means of urban transport, which would necessitate a "cycling culture" to be created [5 and 35]. In the case of Zaragoza, urban planning has been the key to effective inclusion of bicycles by updating tools, such as the Intermodal Transport Plan of 2006. Pending challenges include implementing a more integrated and denser network of cycle lanes, and extending the capacity and cover of the Bizi scheme, which would improve levels of accessibility [36]. The cycle lane network must be extended by building new routes to form a mesh network and provide bicycles with their own space to increase their safety and use [2]. Lastly, it should be emphasised that regulatory processes involving the public, actors and public administrations must also be strengthened to reach agreement on boosting this mode of transport within an integral project for mobility and a sustainable city [12].

\section{Acknowledgements}

This article has been carried out within the framework of the projects "PLOTEG: Herramientas cartograficas para una gobernanza inteligente en las ciudades digitales: Analisis territorial de las condiciones de vida", and "PLOYEG2: 
Indicadores multiescalares y herramientas cartograficas para el analisis de la vulnerabilidad socioeconomica y residencial en areas urbanas: aplicacion al caso de Zaragoza”, funded by Ministry of Economy, R\&D Spanish program Grant agreement no. CSO2013-46863-C3-3-R and CSO2016-74888C4-3-R, and supported by the Aragon Regional Government and the European Social Fund.

\section{References}

[1] RIVERE, M.: Socio-histoire du velo dans l'espace urbain. D'une ecologie politique a une economie mediatique..., Toulouse : Geneve : Saragosse, Doctoral Thesis, 2009, Universite Toulouse II.

[2] DAVID, A., SOSEDOVA, J., PUTZ, L-M., JOLIE, N., KAVRAN, Z.: European Automated Container Terminals, Communications - Scientific Letters of the University of Zilina, vol. 16, No 2, 2014, 41-45, ISSN 1335-4205.6.

[3] ALDRED, R.: The Role of Advocacy and Activism, Parkin, John (Ed.), Cycling and Sustainability, Emerald : Bingley, 2012, 83-108, ISBN 978-1-78052-298-2.

[4] AGERVIG CARSTENSEN, T.; EBERT, A. K.: Cycling Cultures in Northern Europe: From 'Golden Age' to 'Renaissance’, Parkin, J. (Ed.), Cycling and Sustainability, Emerald : Bingley, 2012, 23-58, ISBN 978-1-78052-298-2.

[5] GOSSLING, S.: Urban Transport Transitions: Copenhagen, City of Cyclists, J. of Transport Geography, 33, 2013, 196-206, ISSN 09666923

[6] SNIZEK, B., ALEXANDER, T., NIELSEN, S., SKOV-PETERSEN, H.: Mapping Bicyclists' Experiences in Copenhagen, $J$. of Transport Geography, 30, 2013, 227-233, ISSN 09666923.

[7] BERTOLINI, L., LE CLERQ, F.: Urban Development without More Mobility by Car? Lessons from Amsterdam, a Multimodal Urban Region, Environment and Planning A, 35:4, 2003, 575-589, ISSN 0308518X.

[8] HARMS, L., BERTOLINI, L., TE BROMMELSTROET, M.: Performance of Municipal Cycling Policies in Medium-Sized Cities in the Netherlands since 2000, Transport Reviews, 36:1, 2016, 134-162, ISSN 01441647.

[9] NEDELIAKOVA, E.: KEGA 026ZU-4/2015 Innovative Approaches to the System of Teaching Management in the Study Program Railway Transport with a Focus on Application of the Dynamic Quality Models in Railway Transport.

[10] EUROPEAN COMMISSION: White Paper. Roadmap to a Single European Transport Area - Towards a Competitive and Resource Efficient Transport System. European Commission, Luxembourg, 2011.

[11] HENSON, R; ESSEX, S.: Conception, Organisation et Evaluation de Deseaux de Transport Locaux Durables, Revue internationale des sciences sociales, 2003/2, 176, 2003, 243-260, ISSN 0304-3037.

[12] PUEYO CAMPOS, A.; LOPEZ ESCOLANO, C.; DIESTE HERNANDEZ, J.: L'evolution de Saragosse vers la mobilite durable : le velo comme mode de transport urbain. Consensus, paralysie et conflits d'un modele en effervescence, Sud-Ouest Europeen, 40, 2016, 101-114, ISSN 12764930.

[13] MARQUES, R., HERNANDEZ-HERRADOR, V., CALVO-SALAZAR, M.; GARCIA-CEBRIAN, J. A.: How Infrastructure can Promote Cycling in Cities: Lessons from Seville, Research on Transportation Economics, 53, 2015, 31-44, ISSN 07398859.

[14] BERTOLINI, L., LE CLERQ, F., KAPOEN, L.: Sustainable accessibility: A conceptual framework to integrate transport and land use plan-making. Two test-applications in the Netherlands and a reflection on the way forward, Transport Policy, 12:3, 2005, 207-220, ISSN 0967070X.

[15] HEINEN, E., VAN WEE, B., MAAT, K.: Commuting by Bicycle: An Overview of the Literature, Transport Reviews, 30:1, 2010, 59-96, ISSN 01441647.

[16] PUCHER, J.; DILL, J.; HANDY, S.: Infrastructure, Programs, and Policies to Increase Bicycling: An International Review, Preventive Medicine, 50, 2010, 106-125, ISSN 00917435.

[17] SATO, H., MIWA, T., MORIKAWA, T.: A Study on Use and Location of Community Cycle Stations, Research in Transportation Economics, 53, 2015, 13-19, ISSN 07398859.

[18] ALDRED, R.: Editorial. Cycling and Society, J. of Transport Geography, 30, 2013a, 180-182, ISSN 09666923.

[19] ARRANZ-LOPEZ, A., SORIA-LARA, J. A., LOPEZ-ESCOLANO, C.; PUEYO-CAMPOS, A.: Retail Mobility Environments: A Methodological Framework for Integrating Retail Activity and Non-motorised Accessibility in Zaragoza (in Spain), J. of Transport Geography, 57, 2016, 241-254, in press.

[20] BUEHLER, R., DILL, J.: Bikeway Networks: A Review of Effects on Cycling, Transport Reviews, 36:1, 2015, 9-27, ISSN 01441647. 
[21] JONES, P.: Performing the City: A Body and a Bicycle take on Birmingham, Social and Cultural Geography, 6:6, 2005, 813830, ISSN 14649365.

[22] ALDRED, R.: Incompetent or Too Competent? Negotiating Everyday Cycling Identities in a Motor Dominated Society, Mobilities, 8:2, 2013b, 252-271, ISSN 17450101

[23] PASSAFARO, P., RIMANO, A., PICCINI, M. P., METASTASIO, R., GAMBARDELLA, V., GULLACE, G., LETTIERI, C.: The Bicycle and the City: Desires and Emotions Versus Attitudes, Habits and Norms, J. of Environmental Psychology, 38, 2014, 76-83, ISSN 02724944.

[24] RED DE CIUDADES POR LA BICICLETA.: Barometro Anual de la Bicicleta en Espana, 2015.

[25] PUEYO CAMPOS, A., HERNAANDEZ NAVARRO, M.L.: L'Espagne face a la Grande Recession depuis 2008, Mappemonde, 111, 2013, 1-20, ISSN 17697298.

[26] FISHMAN, E.: Bikeshare: A Review of Recent Literature, Transport Reviews, 36, 2016, 92-113, ISSN 01441647.

[27] SEGUI PONS, J. M., MATEU LLADO, J., RUIZ PEREZ, M., MARTINEZ REYNES, M. R.: Los sistemas de bicicleta publica y la movilidad urbana sostenible. Un analisis en la ciudad de Palma (Mallorca, Islas Baleares), Boletin de la Asociacion de Geografos Espanoles, 71, 2016, 227-245, ISSN 0212-9426.

[28] O 'BRIEN, O.: Bicycle Sharing Systems - Global Trends in Size (Working Papers Series). London : UCL Centre for Advanced Spatial Analysis, 2014. ISSN 1467-1298.

[29] AYUNTAMIENTO DE ZARAGOZA: Plan Intermodal de Transportes. Plan de Movilidad Sostenible de Zaragoza. Ayto. de Zaragoza : Zaragoza, 2006.

[30] UGT-ARAGON, AYTO. DE ZARAGOZA: Reduccion de emisiones de $\mathrm{CO}^{2}$ en los desplazamientos a los centros de trabajo. Ayto. de Zaragoza : Zaragoza, 2013.

[31] LUSKOVA, M., HUDAKOVA, M., BUGANOVA, M.: Importance of Risk Management in Enterprise Quality Planning in Slovakia, ICEEM $2^{\text {nd }}$ intern. conference on economic, education and management. Hong Kong : Education Society. 2012, ISBN 978-988-19750-3-4.

[32] THEYS, J.: Les villes «post-carbone» moteurs de l'economie verte de demain? ESKA, Annales des Mines - Responsabilite et environnement, 61, 2011, 128-133, ISSN 1268-4783.

[33] WOODCOCK, D., BANISTER. D., EDWARDS, P., PRENTICE, A. M., ROBERTS, I.: Energy and Transport, Lancet, 370, 2007, 1078-1088, ISSN 01406736.

[34] PUCHER, J., BUEHLER, R.: Making Cycling Irresistible: Lessons from the Netherlands, Denmark and Germany, Transport Reviews, 28, 2008, 495-528, ISSN 01441647.

[35] JENSEN, A.: Controlling Mobility, Performing Borderwork: Cycle Mobility in Copenhagen and the Multiplication of Boundaries, J. of Transport Geography, 30, 2013, 220-226, ISSN 09666923.

[36] SULGAN, M., SOSEDOVA, J.: Rationalization of Internal Transport Operation in the Intermodal Transport Terminal, Communications - Scientific Letters of the University of Zilina, vol. 18, No 2, 2016, 5-10, ISSN 1335-4205. 